\title{
Effects of Oral Oxytetracycline-Therapy on Wound Progression and Healing Following Aeromonas caviae Infection in Nile Tilapia (Oreochromis niloticus L.)
}

\author{
Anwesha Roy ${ }^{1}$ \\ https://orcid.org/0000-0001-8049-7915 \\ Thangapalam Jawahar Abraham ${ }^{1^{*}}$ \\ https://orcid.org/0000-0003-0581-1307 \\ Meshram Supradhnya Namdeo ${ }^{1}$ \\ https://orcid.org/0000-0002-6046-9703 \\ Jasmine Singha ${ }^{1}$ \\ https://orcid.org/0000-0002-8538-2751 \\ Roy Beryl Julinta ${ }^{1}$ \\ https://orcid.org/0000-0001-6277-1909
}

\section{Satyanarayana Boda ${ }^{2}$}

https://orcid.org/0000-0003-1751-1555

\begin{abstract}
${ }^{1}$ West Bengal University of Animal and Fishery Sciences, Faculty of Fishery Sciences, Department of Aquatic Animal Health, Chakgaria, Kolkata, West Bengal, India; ${ }^{2}$ West Bengal University of Animal and Fishery Sciences, Faculty of Fishery Sciences, Department of Fishery Economics and Statistics, Chakgaria, Kolkata, West Bengal, India.
\end{abstract}

Received: 2018.12.30; Accepted: 2019.06.16

* Correspondence: abrahamtj1@gmail.com; Tel.: +91-9433368328 (TJA)

\section{HIGHLIGHTS}

- Effect of oral OTC-therapy against Aeromonas caviae infection by two challenge routes in Nile tilapia are presented

- The intramuscular challenge effected high mortalities than abrasion-immersion challenge

- The results demonstrated the positive effect of oral OTC-therapy in overcoming the Aeromonas caviae challenge and improving wound healing.

- The extent of damage in untreated Nile tilapia lasted longer in both challenge routes 
Abstract: The effects of oral oxytetracycline (OTC)-therapy against Aeromonas caviae infection as well as the wound progression and healing in intramuscular (IM) and abrasion-immersion (AI) challenged Nile tilapia juveniles were evaluated. The IM challenge caused significantly $(p<0.05)$ high mortalities $(90 \%)$ compared to Al challenge $(40 \%)$. The mortalities recorded in 10 days OTC-fed (72\% in IM group and 30\% in Al group) and untreated Nile tilapia were significantly $(p<0.05)$ high compared to positive $(5-10 \%)$ controls. The reduction in mortalities in OTC-fed Nile tilapia was significant $(p<0.05)$ with no further mortalities during the post-OTC therapy period. In IM group, the black scar disappearance, re-growth of dermal fibrous tissue and skin growth at the ulcerated region were seen on day 10 OTC-therapy. In contrast, the disappearance of wound scar and growth of skin and scales at the abraded area were noted on day 1-4 post-OTC therapy. On day10 post-OTC therapy, complete disappearance of wound scar with a mild spot at the abraded area was noted. The degree of wound healing was faster only initially with OTC- therapy. Nevertheless, the wounds were healed completely even in the surviving untreated tilapia in 30 days with no scars left behind. The extent of mortalities observed in Nile tilapia during the OTC-therapy period is a serious cause for concern, which require prudent planning on its suitability in tropical aquaculture.

Keywords: Aeromonas infection; Abrasion-immersion; Intramuscular injection; Antibiotic therapy; Medicated feed

\section{INTRODUCTION}

Tilapias are known as 'aquatic chicken' due to their wide range of adaptability to the adverse environment and high growth rates. It has become a suitable model fish for aquaculture in tropical and subtropical climates [1]. Tilapias are farmed variedly from rural subsistence farming to large-scale commercial farming in over 100 countries. China is the largest producer of farmed tilapia. Nile tilapia Oreochromis niloticus has become the second largest (by weight) farmed fish crop after the carps, contributing about $8 \%$ of the total finfish produced in 2016 [2]. With the intensification of aquaculture practices, various diseases are surfacing in cultured tilapia $[1,3]$. The major problems are due to bacterial diseases and these include motile Aeromonas septicemia, Pseudomonas septicemia, bacterial hemorrhagic septicemia, streptococcosis, staphylococcosis, vibriosis, mycobacteriosis, columnaris, franciselliosis, edwardsiellosis, yersiniosis and piscirickettsiosis, which caused $>80 \%$ mortalities and severe production losses $[1,4,5]$. Bacterial diseases are generally treated with antibiotics $[1,5,6]$. A wide variety of aquadrugs are used to control the diseases caused by bacteria, fungi, parasites, and viruses [5,7-9]. But in food-fish, only the Food and Drug Administration (FDA) approved drugs may be considered for use [6]. Treatment of Aeromonas is currently limited to two antibiotics, Terramycin ${ }^{\circledR}$, oxytetracycline (OTC), and Romet-30®, a potentiated sulfonamide. The OTC is one of the approved chemotherapeutics as an oral antibacterial to treat specific bacterial diseases in temperate and warm water finfish. Application of unapproved drugs in aquacultured fish poses a potential human health hazard [7,10-12].

The tilapia has become an important species for aquaculture in India and their production had reached a level of 18,000 tonnes in 2016 [13]. Motile Aeromonas spp. are considered as persuasive pathogens that cause mortalities in tilapia and other freshwater fish, when exposed to poor water quality $[5,8,14]$. The effectiveness and safety levels of the FDA approved antibiotics including OTC on temperate finfish have been established [11,12]. Such studies on finfish cultured in tropical conditions are meagre. In our earlier studies, we evaluated the efficacy of OTC in Nile tilapia challenged with Aeromonas hydrophila $[15,16]$. This report presented the results of the isolation, identification, and characterization of Aeromonas spp. from diseased mono-sex Nile tilapia, evaluation of the effectiveness of oral OTC-therapy against $A$. caviae infection as well as the wound progression and healing in challenged Nile tilapia juveniles. 


\section{MATERIAL AND METHODS}

\section{Collection of Diseased Nile Tilapia}

Healthy as well as diseased mono-sex of all male Nile tilapia samples for this study were collected from a fish farm located in Alampur, East Midnapur district (Lat.

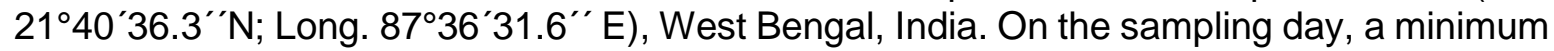
of 60 Nile tilapia was examined for diseases at the pond site as per OIE guidelines [17]. The behavioural abnormalities, gross and clinical signs were recorded. Apparently healthy and morbid Nile tilapia with mouth and opercular haemorrhages, and pale gills ( $n=5$ each) were brought to the laboratory in oxygen filled polythene bags separately for bacteriological analysis.

\section{Bacterial Isolation and Phenotypic Characterization}

At the laboratory, the fish were anaesthetized with clove oil $(50 \mu \mathrm{l} / /$ water), euthanized, dissected aseptically and exposed the kidney. The inocula from the kidney were streaked onto tryptic soy agar (TSA), Rimler Shotts agar base with novobiocin at $10 \mu \mathrm{g} / \mathrm{ml}$ (RSA) and glutamate starch phenol red agar with penicillin G sodium salt of $100 \mathrm{lU} / \mathrm{ml}$ (GSPA; HiMedia, India), and incubated at $30^{\circ} \mathrm{C}$ for $24 \mathrm{~h}$. Both RSA and GSPA plates yielded yellow colour colonies, suggesting motile aeromonads infection. Based on the dominance and definite colony morphology, randomly picked typical colonies ( $n=10$; two isolates from each sample) from the RSA and GSPA plates were subcultured onto TSA plates to obtain the young culture. They were purified by repeated streaking on TSA and maintained on TSA slants. All the strains were then subjected to phenotypic characterization as described in Collins et al. [18]. Taxonomic keys proposed by the University of Idaho, USA (http://www.uiweb.uidaho.edu/microbiology/250/ IDFlowcharts.pdf) were followed for the presumptive identification of bacterial species. The recent works of literature on Aeromonas spp. were also consulted for their identification $[5,19,20]$. Identification of a bacterial strain $\mathrm{CBT}_{1} \mathrm{~K}_{2}$ was also done by the Vitek 2 Compact system (bioMérieux, France). The haemolytic activity of the bacterial strain $\mathrm{CBT}_{1} \mathrm{~K}_{2}$ was done by spot inoculating $20 \mathrm{~h}$ old culture onto the sheep blood agar (HiMedia, India) plate and then incubating for $24 \mathrm{~h}$ at $30 \pm 2^{\circ} \mathrm{C}[18]$.

\section{Bacterial DNA Extraction, PCR Amplification of the 16S rDNA Gene and Phylogeny}

The molecular characterization of the strain $\mathrm{CBT}_{1} \mathrm{~K}_{2}$ was done as described in Adikesavalu et al. [21]. In brief, the 16S rDNA gene was amplified in a master cycler, Pro $S$ (Eppendorf, Germany) using the universal primers (forward primer 8F 5'-AGAGTTTG ATCCTGGCTCAG-3' and reverse primer 1492R 5'-ACGGCTACCTTGTTACGACTT-3') of amplification size 1500 bp [22]. The PCR master-mix (25 $\mu \mathrm{l})$ contained $12.5 \mu \mathrm{l} 2 \mathrm{X}$ PCR TaqMixture (HiMedia), $1.0 \mu \mathrm{l}$ forward primer $8 \mathrm{~F}(10 \mathrm{pMole} / \mu \mathrm{l}), 1.0 \mu \mathrm{l}$ reverse primer $1492 \mathrm{R}$ (10 pMole/ $\mu \mathrm{l}), 1.0 \mu \mathrm{l}$ DNA template and $9.5 \mu \mathrm{l}$ molecular biology grade water. The PCR components were mixed and spun shortly. The amplification was done by initial denaturation at $95^{\circ} \mathrm{C}$ for $2 \mathrm{~min}$, followed by 35 cycles of denaturation at $94^{\circ} \mathrm{C}$ for $45 \mathrm{~s}$, annealing at $55^{\circ} \mathrm{C}$ for $60 \mathrm{~s}$ and extension at $72{ }^{\circ} \mathrm{C}$ for $60 \mathrm{~s}$. The final extension was at $72{ }^{\circ} \mathrm{C}$ for $10 \mathrm{~min}$. The PCR product was analyzed on $1.2 \%$ agarose (HiMedia) gels containing $0.5 \mu \mathrm{g} / \mathrm{ml}$ ethidium bromide in $1 \times$ Tris-acetate-EDTA (TAE) buffer and viewed in a Gel Doc system (G-Box Syngene, UK).

The PCR amplicon of the strain $\mathrm{CBT}_{1} \mathrm{~K}_{2}$ was sequenced at the Genomics Division, Xcelris Labs Ltd, Ahmadabad, India. The sequence was edited by the software DNA Baser Assembler [4.36 version] (www.dnabaser.com). The edited sequence of $1402 \mathrm{bp}$ was compared against the GenBank database of the National Center for Biotechnology Information (NCBI) by using the BLAST (Basic Local Alignment Search Tool) program (http://blast.ncbi.nlm.nih.gov). Nineteen more gene sequences comprising Aeromonas spp. ( $\mathrm{n}=17$ ), viz., Aeromonas caviae LN624814, NR_029252, and CDBK01000019, Aeromonas dhakensis KU248777, Aeromonas rivipollensis FR775967, Aeromonas hydrophila subsp. 
ranae AJ508766, Aeromonas sobria X74683, Aeromonas fluvialis KP997184, Aeromonas veronii LT797513, Aeromonas jandaei X60413, Aeromonas aquariorum JF775500, Aeromonas rivuli NR_116880, Aeromonas piscicola FM999973 and Aeromonas diversa GQ365710, Aeromonas popoffii NR_025317, Aeromonas encheleia AJ458409, and Aeromonas salmonicida subsp. achromogenes X60407, and one strain each of Escherichia coli KP941759 and Bacillus aeries AJ831843 were taken from the NCBI GenBank database. The data analysis and multiple alignments by ClustalW 1.6, the inference of evolutionary history by neighbor-joining method, bootstrap consensus tree from 1000 replicate, computation of evolutionary distances by Kimura 2-parameter method and evolutionary analyses were conducted in MEGA7 [23].

\section{Experimental Fish and Care}

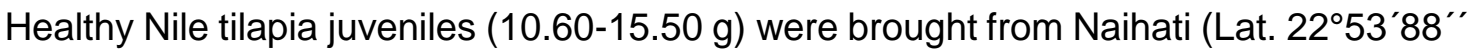
$\mathrm{N}$; Long. 88 $26^{\prime} 62^{\prime \prime}$ E), North 24 Parganas district, West Bengal, India in oxygen filled polythene bags to the laboratory. The fish were acclimatized for an hour followed by disinfection with $5 \mathrm{ppm}$ potassium permanganate for $10 \mathrm{~min}$. One hundred fish were then stocked in each of the $500 \mathrm{~L}$ capacity fibreglass reinforced plastic tanks containing $400 \mathrm{~L}$ clean bore-well water and aerated continuously. The fish were acclimatized for 15 days and fed with commercial pellet feed (CP Pvt. Ltd., India) at the rate of $3 \%$ body weight. The water quality parameters such as dissolved oxygen, total hardness, alkalinity, ammonia, nitrite, and nitrate were determined at intervals following APHA/AWWAWEF methods [24]. The temperature $\left({ }^{\circ} \mathrm{C}\right)$ of the experimental tank waters was recorded by a mercury thermometer. The $\mathrm{pH}$ of water samples was estimated by $\mathrm{pH}$ meter (Eutech Instruments Pte Ltd., India).

\section{Determination of the Lethal Dose $\left(\mathrm{LD}_{50}\right)$ of Aeromonas caviae $\mathrm{CBT}_{1} \mathrm{~K}_{2}$}

The pathogenic potential of $\alpha$-haemolytic $A$. caviae $\mathrm{CBT}_{1} \mathrm{~K}_{2}$ on Nile tilapia juveniles was determined as described in Bharadwaj et al. [25] with minor modification. The challenge route followed was intramuscular (IM) instead of intraperitoneal. Aliquots $(0.1 \mathrm{ml})$ of $A$. caviae cell suspensions from $10^{0}$ to $10^{-4}$ dilutions were injected IM, i.e., on the dorsal side of the body at a $45^{\circ}$ angle on the base of the dorsal fin, in such a way so as to get $10^{8}-10^{4}$ cells/fish. Control fish received $0.1 \mathrm{ml}$ each sterile saline. The challenged fish were maintained in their respective tanks and fed daily with commercial pellet feed on demand. Observations on mortality, external signs of infections and behavioural changes were recorded daily for 4 weeks. The lethal dose at which $50 \%$ of the experimental populations die $\left(\mathrm{LD}_{50}\right)$ was calculated as per Reed and Muench [26].

\section{Preparation of Oxytetracycline-Medicated Feed by Top Dressing and Oral Therapy}

The OTC-medicated feed at the recommended dose and guidelines of USFDA [11,12] for feeding Nile tilapia at 3\% of the body weight (BW) was prepared by mixing $2 \mathrm{~g}$ OTC (oxytetracycline dihydrate, HiMedia) in $5 \mathrm{ml}$ vegetable oil and then admixed with $1 \mathrm{~kg}$ basal feed in an airtight plastic container (OTC-feed). The control feed was prepared by mixing 5 $\mathrm{mL}$ of vegetable oil alone with $1 \mathrm{~kg}$ basal feed in an airtight plastic container. The above feeds were mixed thoroughly for uniform mixing. The feeds were, then, uniformly spread, dried under the fan for $24 \mathrm{~h}$, and stored in airtight plastic containers separately at room temperature.

\section{Efficacy of Oral Oxytetracycline-Therapy Against Aeromonas caviae Infection Intramuscular Challenge}

The experiment was carried out in plastic tanks of size $(\mathrm{L} 58 \times \mathrm{H} 45 \times \mathrm{W} 45 \mathrm{~cm})$ with Nile tilapia juveniles $(13.40 \pm 0.48 \mathrm{~g}$ and $10.39 \pm 0.67 \mathrm{~cm})$. Prior to use, the tanks were scrubbed, cleaned with chlorinated water $(200 \mathrm{ppm})$, flushed thoroughly with fresh water, dried for 3 days and filled with clean water to a volume of $80 \mathrm{~L}$ each. After three days of conditioning, each tank was stocked with 20 experimental fish from the acclimatized stocks. The Nile 
tilapia in plastic tanks were grouped into 4 groups, in triplicate, viz., group 1: negative control; group 2: positive control; group 3: $0 \mathrm{~g}$ OTC/kg feed (untreated); group 4: $2 \mathrm{~g}$ OTC/kg feed (OTC-treated). The tanks were labelled and covered with nylon netting for adequate protection. The Nile tilapia were fed with $3 \%$ body weight. About $50 \%$ of the water was exchanged and waste feed and faecal materials were removed daily. The physicochemical water parameters were measured at every $5^{\text {th }}$ day to maintain the optimal level throughout the experiment. After acclimatization for 7 days in the experimental tanks, the Nile tilapia of groups 3 and 4 were injected IM at the base of the dorsal fin with $0.1 \mathrm{ml}$ each of $A$. caviae cell suspension at $\approx 10^{8}$ cells/fish. The Nile tilapia of group 2 were injected with $0.1 \mathrm{ml}$ each sterile saline and served as a positive control. The challenged Nile tilapia were then transferred to their respective tanks.

\section{Abrasion-Immersion Challenge}

The preparation of experimental tanks, stocking of experimental Nile tilapia groups $(10.89 \pm 0.08 \mathrm{~g}$ and $8.71 \pm 0.51 \mathrm{~cm})$, care and maintenance are as described in the previous section. After acclimatization for 7 days in the experimental tanks, scales of all Nile tilapia from groups 2, 3 and 4 were scrapped off gently with a scalpel from caudal peduncle to the pectoral fin, i.e., in the opposite direction (abraded) as described in Adikesavalu et al. [21]. The abraded Nile tilapia from groups 3 and 4 were then immersed in $A$. caviae suspension $\left(1000 \mathrm{ml}\right.$ ) containing $10^{7} \mathrm{CFU} / \mathrm{ml}$ for $1 \mathrm{~h}$. The abrasion-immersion (Al) challenged Nile tilapia were then transferred to their respective tanks.

\section{Oral Oxytetracycline-Therapy}

The group 1 (healthy, non-abraded or non-injected) and group 2 (abraded or saline injected) were kept undisturbed and served as negative and positive controls, respectively. The fish of groups 1-3 were fed with control feed at 3\% of BW twice daily throughout the experimental period of 39 days. The challenged Nile tilapia were starved on the day of IM or Al challenge (i.e., on day 8). The Nile tilapia of group 4 (IM or Al challenged) were fed with control feed during the pre-treatment period (day 1-7) and post-treatment period (day 19-39). During the treatment period of 10 days (day $9-18$ ), they were fed with OTC-feed at $3 \%$ BW in order to achieve the recommended dose of $60 \mathrm{mg} \mathrm{OTC} / \mathrm{kg}$ fish biomass/day. The unconsumed feed, if any, in each tank was removed after 3 hours of feeding. Observations on mortality, external signs of infections and behavioural changes were recorded daily.

\section{Wound Progression and Healing}

The wounds at the site of IM injection or abrasion were digitally photographed during the treatment regime. Tissue damages were assessed using a score ranging from 0 to 6 , depending on the degree and extent of damage based on the scale proposed by Bernet et al. [27]. The extent of wound progression and healing was qualitatively classified as 0 : No damage or undamaged with no pathological importance; 0.5 : Very mild damage with little or no pathological importance; 1: Very mild damage with minimal pathological importance; 2 : Mild damage with minimal pathological importance; 4: Moderate damage with moderate pathological importance and 6: Severe damage with marked pathological importance. Intermediate values were also considered.

\section{Statistical Analyses}

The results of the different experiments are expressed as the mean \pm standard deviation and analyzed using the Statistical Package for Social Sciences (IBM-SPSS) Version: 22.0, considering a probability level of $\mathrm{P}<0.05$ for the significance of the collected data. The differences in Nile tilapia mortalities among the treatment groups of different challenge route were tested by repeated measures ANOVA with Greenhouse-Geisser correction and Bonferroni correction for pair-wise comparison. The qualitative scores of wound progression and healing within and/or among the challenge groups were analyzed by related samples Friedman ANOVA and the independent samples by Mann Whitney $U$ test. 


\section{RESULTS}

\section{Characterization of Bacterial Flora of Diseased Nile Tilapia}

The gross and clinical signs observed in the diseased Nile tilapia were lethargy, sluggish behaviour, erratic movement, loss of mucus, pale gills and mouth and opercular haemorrhages. The infection rate was about $18 \%$ and the mortality was negligible. The kidney upon dissection was observed to be pale. All the 10 bacterial strains associated with the diseased Nile tilapia were presumptively identified on the basis of their growth on RSA and GSPA, and phenotypic characterization (Table 1) as members of the genus Aeromonas, viz., A. hydrophila $(\mathrm{n}=3)$, A. caviae $(\mathrm{n}=2), A$. veronii $(\mathrm{n}=3)$, A. bestiarum $(\mathrm{n}=1)$ and $A$. schuberti $(\mathrm{n}=1)$. The Vitek 2 compact system identified the bacterial strain $\mathrm{CBT}_{1} \mathrm{~K}_{2}$ as $A$. caviae with $98 \%$ probability (Table 2 ). It produced the $\alpha$-haemolytic reaction on sheep blood agar. The identity of $A$. caviae $\mathrm{CBT}_{1} \mathrm{~K}_{2}$ was further confirmed by molecular analysis. In $1.2 \%$ agarose gel electrophoresis of the PCR amplified product, a $1.5 \mathrm{kbp}$ band was obtained. The phylogenetic tree generated by the neighbor-joining Kimura-2 parameter of the 16S rDNA gene sequences revealed the clustering of all Aeromonas spp. as a separate branch (Figure 1 ). All the strains of $A$. caviae were clustered together, distinctly separated from other Aeromonas spp. The gene sequence of $A$. caviae $\mathrm{CBT}_{1} \mathrm{~K}_{2}(1402 \mathrm{bp})$ showed $100 \%$ DNA homology with $A$. caviae-TWW3 (NCBI accession number LN624814). The 16S rDNA gene sequence of $A$. caviae $\mathrm{CBT}_{1} \mathrm{~K}_{2}$ has been deposited in the NCBI GenBank database, USA under the accession number MH581386.

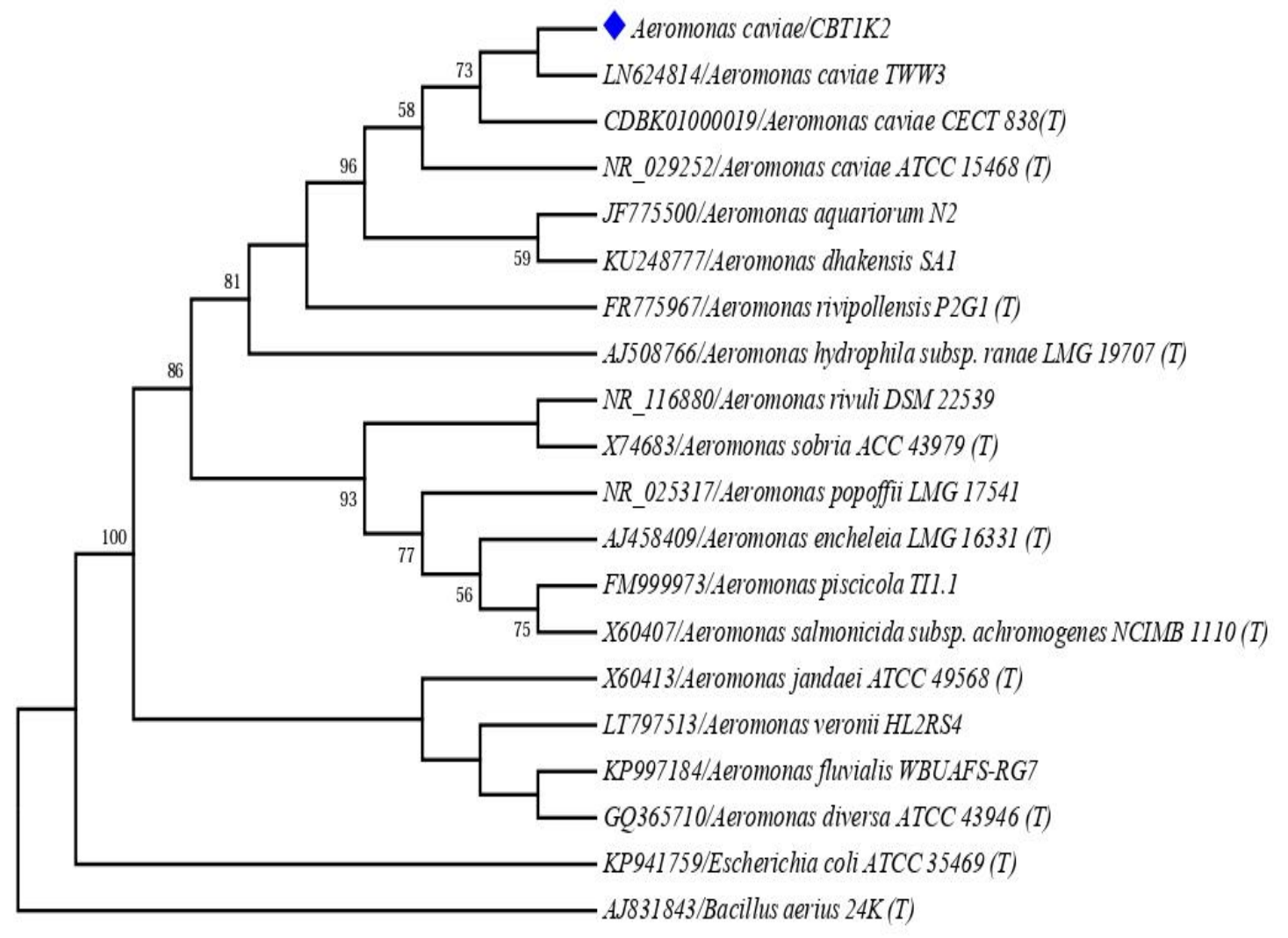

Figure 1 - Phylogenetic tree generated by neighbor-joining Kimura-2 parameter of the 16S rDNA gene sequence of Aeromonas caviae $\mathrm{CBT}_{1} \mathrm{~K}_{2}$. Numbers at nodes indicate bootstrap confidence value (1000 replication) 
Table 1 - Phenotypic characterization of motile Aeromonas spp. isolated from diseased Nile tilapia by conventional biochemical tests

\begin{tabular}{|c|c|c|c|c|c|}
\hline $\begin{array}{l}\text { Biochemical } \\
\text { characteristics }\end{array}$ & $\begin{array}{l}\text { Aeromonas } \\
\text { bestiarum } \\
\text { (1) }\end{array}$ & $\begin{array}{l}\text { Aeromonas } \\
\text { caviae } \\
(2)\end{array}$ & $\begin{array}{l}\text { Aeromonas } \\
\text { hydrophila } \\
\text { (3) }\end{array}$ & $\begin{array}{l}\text { Aeromonas } \\
\text { schuberti } \\
\text { (1) }\end{array}$ & $\begin{array}{l}\text { Aeromonas } \\
\text { veronii } \\
(3)\end{array}$ \\
\hline Gram reaction & - & - & - & - & - \\
\hline Morphology & $\mathrm{R}$ & $\mathrm{R}$ & $\mathrm{R}$ & $\mathrm{R}$ & $\mathrm{R}$ \\
\hline Oxidase & + & + & + & + & + \\
\hline $\mathrm{O} / \mathrm{F}$ reaction & $+/+$ & $+/+$ & $+/+$ & $+/+$ & $+/+$ \\
\hline Motility & + & + & + & + & + \\
\hline Gas from glucose & + & - & + & - & + \\
\hline Indole & + & + & + & - & + \\
\hline $\begin{array}{l}\text { Voges-Proskauer } \\
\text { reaction }\end{array}$ & + & - & + & - & + \\
\hline Citrate utilization & - & + & + & + & + \\
\hline Starch hydrolysis & + & + & + & + & + \\
\hline Esculin hydrolysis & + & + & + & - & + \\
\hline Arabinose utilization & - & + & + & - & - \\
\hline Cellobiose utilization & - & + & - & - & + \\
\hline Sorbitol & - & - & + & - & - \\
\hline Lysine decarboxylase & + & - & + & + & + \\
\hline $\begin{array}{l}\text { Ornithine } \\
\text { decarboxylase }\end{array}$ & - & - & - & - & + \\
\hline Arginine dihydrolase & + & + & + & + & - \\
\hline Haemolysis & $\alpha$ & $\alpha$ & $\beta$ & $\alpha$ & $\beta$ \\
\hline
\end{tabular}


Table 2 - Phenotypic characterization of Aeromonas caviae $\mathrm{CBT}_{1} \mathrm{~K}_{2}$ isolated from diseased Nile tilapia by Vitek-2 Compact system (bioMérieux, France)

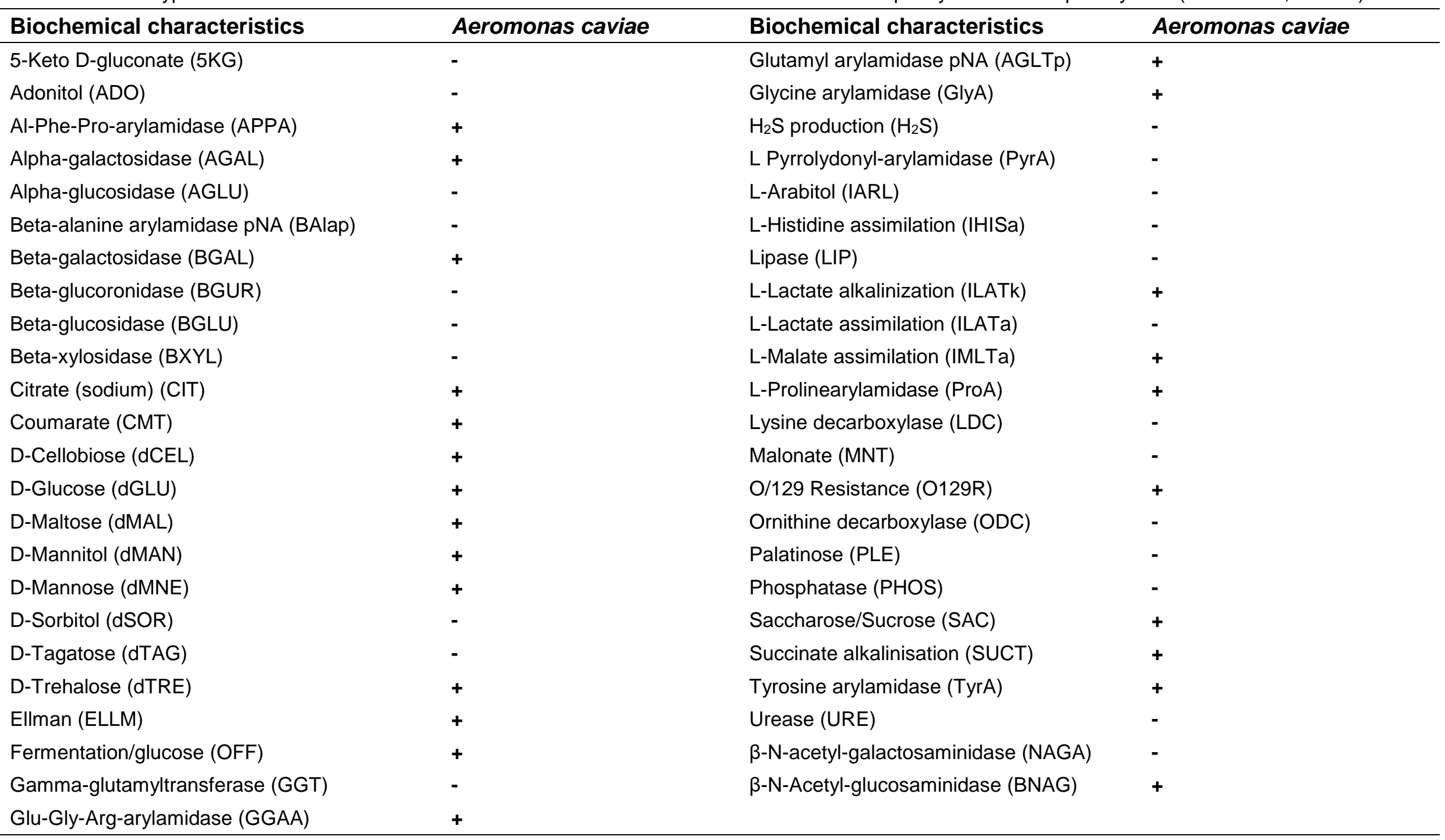




\section{Lethal Dose $\left(\mathrm{LD}_{50}\right)$ of Aeromonas caviae $\mathrm{CBT}_{1} \mathrm{~K}_{2}$}

At a challenge dose of $1.70 \times 10^{9} \mathrm{~A}$. caviae cells/fish, $60 \%$ mortality was observed within $12 \mathrm{~h}$ of injection. In Nile tilapia injected with lower concentrations of $A$. caviae, no mortalities were observed. Often they were lying at the bottom of the tank and listless. The $L_{50}$ value of A. caviae $\mathrm{CBT}_{1} \mathrm{~K}_{2}$ was estimated as $6.76 \times 10^{8}$ cells/fish.

\section{Efficacy of Oral Oxytetracycline-Therapy Against Aeromonas caviae Infection}

\section{Intramuscular Challenge}

Figure 2 depicted the mortality pattern in $A$. caviae challenged and OTC-fed Nile tilapia juveniles on day 10 OTC-feeding in comparison with other groups. Significant differences in Nile tilapia mortalities were observed among the treatment groups $(p<0.05)$. Significantly high mortalities were recorded both in OTC-fed $(72 \pm 3 \%)$ and untreated Nile tilapia $(90 \pm 5 \%)$ compared to the positive control. The difference in the mortalities of OTC-fed and untreated Nile tilapia was also significant $(p<0.05)$ (Figure 2$)$. No mortalities were recorded during the post-treatment period in OTC-fed group. The qualitative rating of wound progression and healing in A. caviae infected and OTC-treated Nile tilapia for 10 days is presented in Table 3. Tissue reddening, inflammation, and skin peeling at the site of injection, and open subepithelial wounds started to become obvious within 24 and $48 \mathrm{~h}$ of $A$. caviae challenge, respectively. A membrane over the wound was observed on $3 \mathrm{dpi}$. With OTC therapy, reddening and inflammation subsided with the formation of a black scar in the ulcerated area. The areas surrounding the wound became very dark in 7 days of OTC-therapy. All wounds examined were closed with the development of skin and scales within 12 days of injection or day 1 post-OTC therapy (dpt). The black scar disappearance, the onset of dermal fibrous tissue re-growth and development of skin at the ulcerated scar region were seen on $15 \mathrm{dpi}(4$ dpt). On $21 \mathrm{dpi}(10 \mathrm{dpt})$, complete disappearance of the black scar with mild depression at the site of injection was noticed. Full recovery of normal skin architecture was reached within 29 dpi (Table 3; Figure 3). The differences in the rate of healing between the OTC treated and untreated Nile tilapia, more particularly from 4 dpi to $15 \mathrm{dpi}$, i.e., the day 3 OTC-therapy to day 4 post-OTC therapy, were significant $(p<0.05)$.

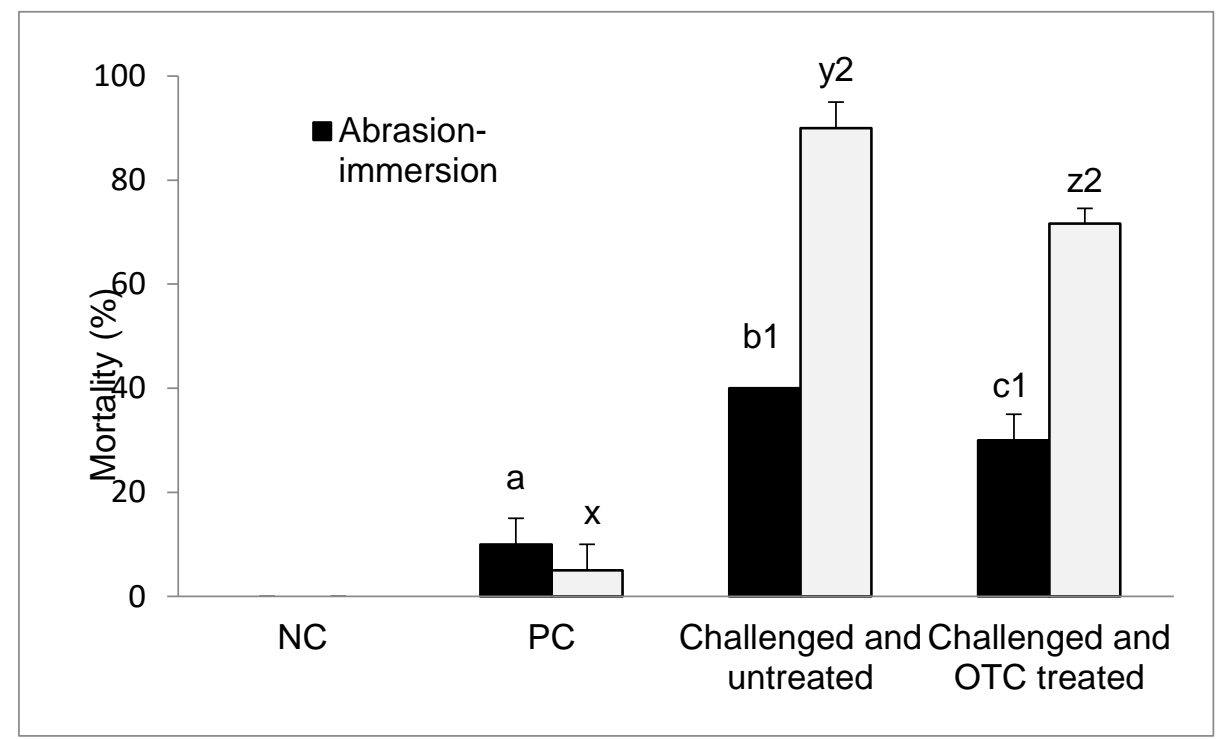

Figure 2 - Mortalities in Nile tilapia juveniles challenged with Aeromonas caviae by abrasionimmersion and/or intramuscular injection methods and fed subsequently with oxytetracycline (OTC; $2 \mathrm{~g} / \mathrm{kg}$ feed) on day 10 OTC-feeding. NC: Negative control; PC: Positive control. a-c: Bars sharing uncommon alphabets within the abrasion-immersion group differed significantly $(p<0.05)$. $x-z$ : Bars sharing uncommon alphabets within the intramuscular injection group differed significantly $(p<0.05)$. 1-2: Bars sharing uncommon numerals within the challenged and untreated or challenged and OTC-treated groups differed significantly $(p<0.05)$. 
Table 3 - The rate of wound progression and healing in Nile tilapia juveniles challenged with Aeromonas caviae and fed oxytetracycline feed for 10 days during the treatment regime

\begin{tabular}{lllll}
\hline \multirow{2}{*}{ Treatment days } & \multicolumn{3}{l}{ Wound progression and healing score } \\
\cline { 2 - 5 } & \multicolumn{2}{l}{ Intramuscular challenge } & \multicolumn{2}{l}{ Abrasion-immersion challenge } \\
\cline { 2 - 5 } & OTC-treated & Untreated & OTC-treated & Untreated \\
\hline 0 & $0.00 \pm 0.00$ & $0.00 \pm 0.00$ & $0.00 \pm 0.00$ & $0.00 \pm 0.00$ \\
$1 \mathrm{dpi} / \mathrm{dpa}$ & $4.00 \pm 0.00^{\mathrm{a}}$ & $4.00 \pm 0.00^{1}$ & $6.00 \pm 0.00^{\mathrm{\beta}}$ & $6.00 \pm 0.00^{2}$ \\
$2 \mathrm{dpi} / \mathrm{dpa}$ & $6.00 \pm 0.00$ & $6.00 \pm 0.00$ & $6.00 \pm 0.00$ & $6.00 \pm 0.00$ \\
$3 \mathrm{dpi} / \mathrm{dpa}(2 \mathrm{dot})$ & $6.00 \pm 0.00$ & $6.00 \pm 0.00$ & $6.00 \pm 0.00$ & $6.00 \pm 0.00$ \\
$4-5 \mathrm{dpi} / \mathrm{dpa}(3-4 \mathrm{dot})$ & $2.30 \pm 0.50^{\mathrm{aa}}$ & $4.00 \pm 0.00^{\mathrm{b} 1}$ & $4.00 \pm 0.00^{\mathrm{a}}$ & $6.00 \pm 0.00^{\mathrm{b} 2}$ \\
$6-8 \mathrm{dpi} / \mathrm{dpa}(5-7 \mathrm{dot})$ & $2.00 \pm 0.00^{\mathrm{a}}$ & $4.00 \pm 0.00^{\mathrm{b}}$ & $2.00 \pm 0.00^{\mathrm{a}}$ & $4.00 \pm 0.00^{\mathrm{b}}$ \\
$12 \mathrm{dpi} / \mathrm{dpa}(1 \mathrm{dpt})$ & $1.00 \pm 0.00^{\mathrm{a}}$ & $2.80 \pm 0.50^{\mathrm{b}}$ & $1.00 \pm 0.00^{\mathrm{a}}$ & $3.80 \pm 0.50^{\mathrm{b}}$ \\
$15 \mathrm{dpi} / \mathrm{dpa}(4 \mathrm{dpt})$ & $1.00 \pm 0.00^{\mathrm{a}}$ & $2.00 \pm 0.00^{\mathrm{b}}$ & $0.90 \pm 0.30^{\mathrm{a}}$ & $2.00 \pm 0.00^{\mathrm{b}}$ \\
$21 \mathrm{dpi} / \mathrm{dpa}(10 \mathrm{dpt})$ & $0.50 \pm 0.00$ & $0.90 \pm 0.30$ & $0.50 \pm 0.00^{\mathrm{a}}$ & $1.00 \pm 0.00^{\mathrm{b}}$ \\
$29 \mathrm{dpi} / \mathrm{dpa}(18 \mathrm{dpt})$ & $0.00 \pm 0.00$ & $0.00 \pm 0.00$ & $0.00 \pm 0.00$ & $0.00 \pm 0.00$ \\
\hline
\end{tabular}

*: As per the scale proposed by Bernet et al. [27]. dpi: day post-injection; dpa: day post-abrasion; dot: day OTC-therapy; dpt: day post-OTC therapy; a-b: Values sharing uncommon alphabets within a column between the OTC-treated and untreated fish of the respective challenge group differ significantly $(p<0.05)$; $\alpha-\beta$ : Values sharing uncommon symbols within a row between the OTC-treated fish of the two challenge routes differ significantly $(p<0.05) ; 1-2$ : Values sharing uncommon numerical within a row between the untreated fish of the two challenge routes differ significantly $(p<0.05)$.

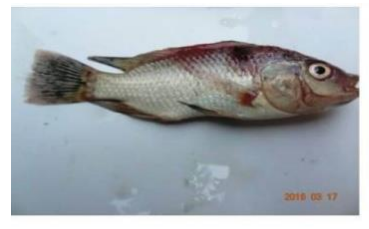

1 dpi

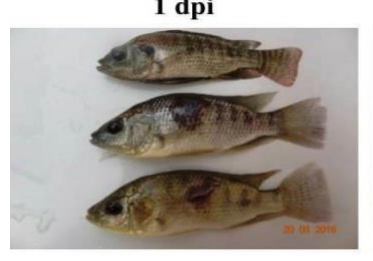

4 dpi (3 dot)

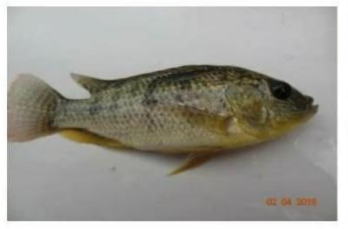

15 dpi (4 dpt)

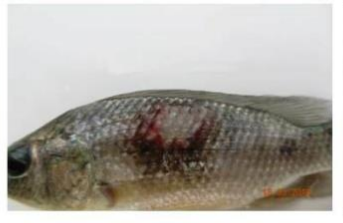

2 dpi

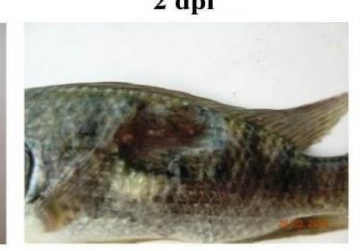

8 dpi ( 7 dot)

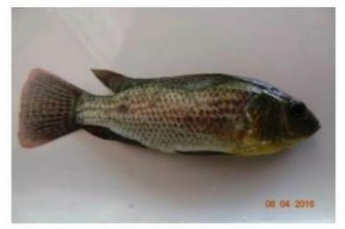

21 dpi (10 dpt)

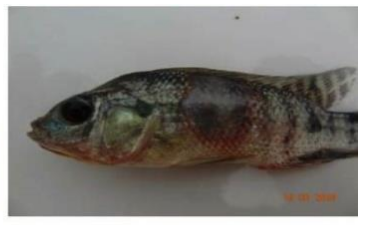

3 dpi ( 2 dot)

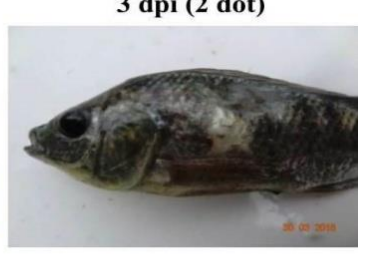

12 dpi (1 dpt)

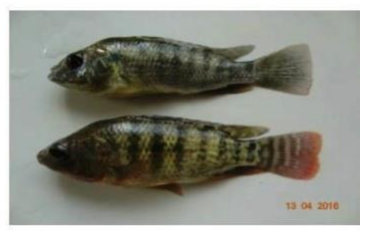

29 dpi (18 dpt) Fig. 3

Figure 3 - Digital images showing the wound progression and healing in Aeromonas caviae IM challenged, and oxytetracycline feed fed Nile tilapia juveniles during the treatment regime. dpi: day post-injection; dot: day OTC treatment; dpt: day post-OTC treatment. 


\section{Abrasion-Immersion Challenge}

As shown in Figure 2, significant differences in Nile tilapia mortalities were observed among the treatment groups $(p<0.05)$. The mortalities in Al challenged Nile tilapia increased significantly $(p<0.05)$ in untreated $(40 \pm 0 \%)$ and OTC-fed $(30 \pm 5 \%)$ groups compared to the positive control on day 10. The difference in the mortalities between the OTC-fed and untreated Nile tilapia were significant $(p<0.05)$. During the post-treatment period, no mortalities were recorded in OTC-fed group; while it was increased to $50 \%$ in untreated Nile tilapia. Further, the Al challenge caused significantly low mortalities compared to IM challenge $(p<0.05)$. Loss of scales at the site of abrasion, skin peeling with the haemorrhagic lesion, pale gills, haemorrhages in the opercular region, tail rot, darkening of the body colour, tissue inflammation and tissue softening were noted on $1 \mathrm{dpa}$. The development of more flaccid tissue at the site of abrasion was noticed on $2 \mathrm{dpa}$. A reduction in red discolouration and inflammation at the site of abrasion was noted on $3 \mathrm{dpa}$. Further reduction in the discolouration was seen on 5 dpa (day 4 OTC-therapy (dot)). Closure of wounds with the development of normal tissue colour and the skin layer was eminent within 6 days of wounding or 5 days of OTC-therapy (dot). The disappearance of wound mark and development of skin at the abraded area were seen on 12-15 dpa (1-4 dpt). The complete disappearance of wound scar with a mild spot at the site of abrasion was noted on $21 \mathrm{dpa}$ (10 dpt). Full recovery of normal skin architecture was reached within $29 \mathrm{dpa}$ (Table 3). The qualitative scores of wound healing between the OTC-fed and the untreated Nile tilapia of this challenge group were found to be significantly different, noticeably on and from 4 dpa to $21 \mathrm{dpa}(\mathrm{p}<0.05)$. The differences in the rate of healing between the OTC-treated Nile tilapia of two challenge routes were significant $(p<0.05)$ on $1 \mathrm{dpi} / \mathrm{dpa}$ and $4-5 \mathrm{dpi} / \mathrm{dpa}$, so also in untreated Nile tilapia (Table 3; Figure 4). The freshly dead fish of both challenges were subjected to bacteriology and necropsy. Internally, pale kidney and liver, discoloured, liquefied and haemorrhagic internal organs were observed. Bacteriological samples taken from the kidney of freshly dead Nile tilapia revealed the exclusive growth of yellow colour colonies on RSA and GSPA, which confirmed Aeromonas infection.

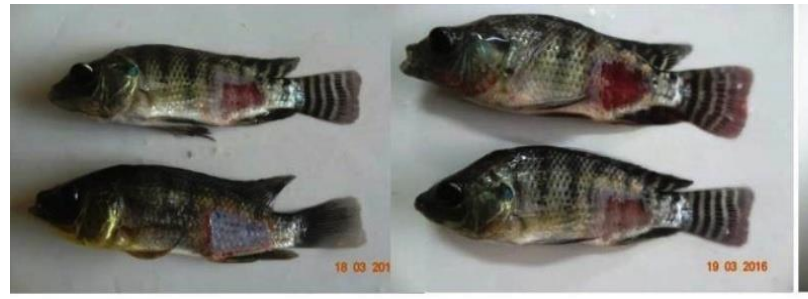

1 dpa
2 dpa

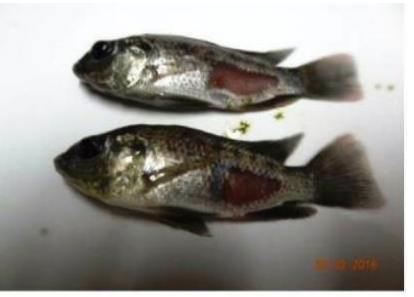

3 dpa (2 dot)

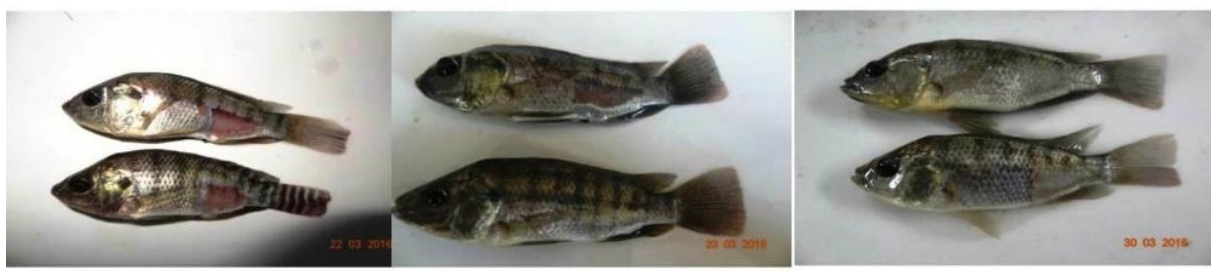

5 dpa (4 dot)

6 dpa (5 dot)

12 dpa (1 dpt)

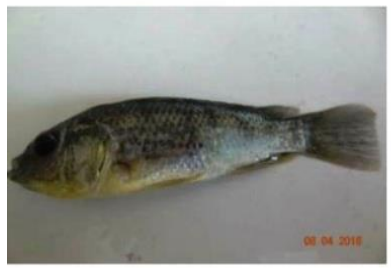

15 dp (4 dpt)

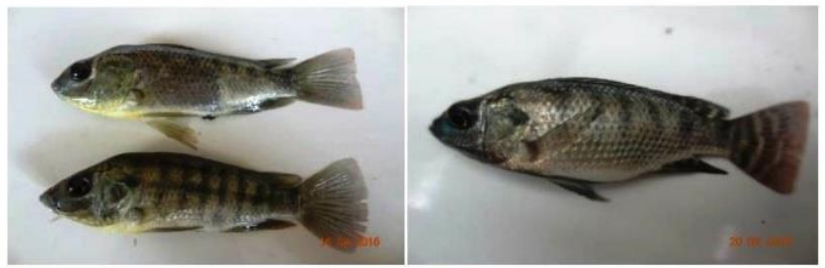

21 dp (10 dpt)

29 dpa (18 dpt) Fig. 4 
Figure 4 - Digital images showing the wound progression and healing in Aeromonas caviae Al challenged, and oxytetracycline feed fed Nile tilapia juveniles during the treatment regime. dpa: day post-abrasion; dot: day OTC treatment; dpt: day post-OTC treatment.

\section{DISCUSSION}

The important factor in diagnosing and managing the disease is the identification of the exact causative agent. The gross and main clinical signs exhibited by the diseased Nile tilapia were suggestive of bacterial infection [5]. The typical bacterial growth on specific media of RSA and GSPA, and conventional biochemical characteristics revealed motile Aeromonas spp. infection involving $\beta$-haemolytic $A$. hydrophila and $A$. veronii, and a-haemolytic $A$. caviae, $A$. bestiarum and $A$. schuberti. The observations on the onset of a disease condition in cultured Nile tilapia with $18 \%$ infection rate and negligible mortality corroborate the conditions recorded in an Egyptian tilapia farm due to motile Aeromonas septicemia [11]. Aeromonas infection is mainly initiated due to environmental stress factors such as high water temperatures, ammonia and nitrite levels, $\mathrm{pH}$ disturbances, organic loads, low dissolved oxygen levels, overcrowding, heavy parasite burdens, spawning activity, seining activities, rough handling and transport $[5,8]$. The observations on the pale kidney and other internal organs damage, and isolation of $\alpha$ - and $\beta$-haemolytic Aeromonas spp. in the kidney indicated a systemic infection in Nile tilapia. The $\alpha$ - and $\beta$-haemolytic activities established the virulence potential of Aeromonas spp. from Nile tilapia.

The association of $A$. caviae in the motile aeromonads infection of Nile tilapia of the present study was further confirmed by Vitek 2 and $16 \mathrm{~S}$ rDNA gene sequence analyses. The $\mathrm{LD}_{50}$ value of $A$. caviae strain was estimated as $6.76 \times 10^{8}$ cells/fish when injected IM, which is advantageous for the successful experimental challenge and induction of clinical signs and symptoms. The strains that exhibit $\mathrm{LD}_{50} \geq 10^{8} \mathrm{CFU} /$ fish are considered avirulent according to Santos et al. [28]. Nevertheless, it had the ability to cause bacteremia, haemolysis, and mortality at higher challenge doses. Schlotfeldt and Alderman [29] opined that the effects of $A$. caviae on fish can vary according to their resistance to the infection.

Antibiotics reportedly reduce the level of infection either by preventing the multiplication of pathogens or by retarding the growth, consequently, the fish can overcome the disease [5]. The OTC is an approved antibiotic for use in aquaculture, but only in certain types of aquatic animals and only to treat certain diseases [10-12]. Attempts by different challenge models yielded varying degrees of success [4,30]. Skin abrasions or scale removal may enhance the success of disease establishment. Ventura and Grizzle [31] produced systemic infections more readily among channel catfish Ictalurus punctatus by abrading their skin prior to exposing the fish to the bacterium. In this study, the therapeutic effects of OTC by two experimental $A$. caviae infection routes in a similar line with our earlier studies on $A$. hydrophila[15,16] were found almost the same in Nile tilapia. On day 10 oral OTC-therapy, the AI and IM challenged Nile tilapia recorded $30 \%$ and $72 \%$ mortalities, respectively. On the other hand, during a similar period, the respective mortalities observed in untreated Nile tilapia were $40 \%$ and $90 \%$ by $\mathrm{Al}$ and IM challenge routes. The observed mortalities in the IM group were 2.25-2.40 folds higher than the Al group due to the higher challenge dose. The observed significant reduction in Nile tilapia mortalities of both challenge routes upon OTC-therapy as per the approved dose and dosage $[11,12]$ compared to the untreated Nile tilapia, to some extent, indicated the usefulness of antibiotic therapy. Except for the total hardness $(742.20 \pm 19.83 \mathrm{mg} / \mathrm{l})$ and alkalinity $(358.60 \pm 25.81 \mathrm{mg} / \mathrm{l})$, all other parameters such as temperature $\left(28.52 \pm 1.64^{\circ} \mathrm{C}\right)$ dissolved oxygen $(4.64 \pm 0.11 \mathrm{mg} / \mathrm{l})$, ammonia $(0.005 \pm 0.002$ $\mathrm{mg} / \mathrm{l})$, nitrite $(0.48 \pm 0.40 \mathrm{mg} / \mathrm{l})$ and nitrate $(0.43 \pm 0.17 \mathrm{mg} / \mathrm{l})$ were well within the optimum range thus ruling out the role of water quality parameters in these mortalities. The observed high mortalities in Nile tilapia juveniles $(90 \%)$ during the oral OTC-therapy following IM challenge at a dose of $\approx 10^{8} \mathrm{CFU} /$ fish compared to the pathogenicity trials $(60 \%)$ could be attributed to the use of different fish stocks with varied immunity status. Likewise, varying degrees of resistance in Nile tilapia to $A$. caviae infection was noted earlier [29]. The results, 
thus, demonstrated that IM challenge was more effective in eliciting the pathological changes and mortalities. Though the dose of OTC administered in the present study differed from some of the previous studies $[16,32]$ the vital results were found to be quite similar. Equally, Haque et al. [33] observed the effectiveness of OTC $(2 \mathrm{~g} \mathrm{OTC} / \mathrm{kg}$ feed $)$ in reducing the bacterial load in fish under artificial culture condition. They suggested that the use of OTC twice daily to reduce the bacterial load in fish and for maintaining the fish health.

A selection of digital images gave examples of the disease progression and healing process at different periods of oral OTC-therapy in Nile tilapia. The tissue damages and open subepithelial wounds started to become obvious within 1 and 2 days of IM challenge with $A$. caviae, respectively. A membrane over the wound was observed on $3 \mathrm{dpi}$. With OTC therapy, reddening and inflammation subsided with the formation of the black scar in the ulcerated area. The areas surrounding the wound became very dark on the day 6 OTC-therapy may be due to the increased number of melanocytes and their activities after the injury [34]. The observations on the wound darkening corroborate Rehulka[35], who observed discolouration of skin in rainbow trout artificially-infected with $A$. caviae. The black scar disappearance, the onset of dermal fibrous tissue re-growth and development of skin at the ulcerated scar region as seen on day 10 OTC-therapy indicated regeneration of the muscle tissue. All wounds were closed on day 4 post-OTC therapy. The repair of dermal and muscle structure took much longer time in comparison with the epidermis. This corroborates Quilhac and Sire [36], who observed a rapid differentiation of the epidermal basal layer cells when examining the dynamics of the re-epithelialization process in a wounded cichlid fish. Similarly, the findings of Ashley et al. [37] demonstrated temporal precedence of epidermal over the dermal repair in fish. Complete disappearance of the black scar with mild depression at the site of injection was noticed subsequently. The depression at the site of injection during the recovery period, as observed on day 10 post-OTC therapy, is an indication that the tissue re-growth had not reached steady state levels. Likewise, complete re-growth of a new scale with the size and characteristics of a mature scale within a few weeks was observed $[38,39]$. Full recovery of normal skin architecture was reached within $30 \mathrm{dpi}$. On the wounded regions, no scars were left behind, which represent the more advanced healing progression in Nile tilapia. Though the rate of wound healing was initially faster in OTC-treated fish, the wounds were healed completely even in the surviving untreated fish within 30 days. In earlier studies, the main effect was generally seen on fibrous tissue, including the repair of damaged dermal fibres, revascularization, and the re-establishment of normal dermal and muscle structure during the wound healing process $[40,41]$. In similar studies on incisional wounds in catfish Clarias batrachus, the epidermis became normal by 32 days [42]; while the $A$. hydrophila induced wounds in Nile tilapia by IM challenge, the epidermis became normal by 30 days[16].

In Al challenged Nile tilapia juveniles, body darkening, inflammation, tissue damage, reddening, softening and loss of scales at the site of abrasion were noted on $1 \mathrm{dpa}$, which became more flaccid at the site of abrasion on 2 dpa. Likewise, Vieira et al. [43] recorded damage in the epidermis, dermis and scale pocket upon the removal of scales of sea bream (Sparus auratus). According to them, the latter two tissues became exposed to the ambient water and the epidermis which remained attached to the dermis hung loose. A reduction in red discolouration and inflammation at the site of abrasion was noted within 2 days of OTC-therapy. A modest development of normal tissue colour and skin layer at the abraded area was recorded on day 3 OTC-therapy. The results are, more or less, similar to Vieira et al. [43], whose histological analysis of skin/scales revealed re-epithelisation and formation of the scale pocket on day 3 of scale removal and a visible thin regenerated scale on day 7 of scale removal. The disappearance of wound scar and development of skin, as well as the scales at the abraded area, were seen on day 1-4 post-OTC therapy (12-15 dpa) and 21 dpa in untreated Nile tilapia. On $21 \mathrm{dpa}$, complete disappearance of wound scar with a mild spot at the site of abrasion was noted in OTC-treated Nile tilapia. On the other hand, the extent of damage and the pathological importance of control feed fed Nile tilapia lasted longer in both challenge routes. Nevertheless, full recovery was achieved within a month of 
injection or abrasion. The results, thus, demonstrated that the degree of wound healing was promoted by OTC-medicated feed, which was more prominent during the treatment periods. Slow wound healing, as was observed in untreated Nile tilapia, may expose them to an increased risk of infection with other pathogens.

\section{CONCLUSION}

In general, the $A$. caviae challenge and oral OTC-therapy in Nile tilapia under laboratory condition provided some useful information on the bacterial disease treatment. It demonstrated the positive effect of OTC-feeding in overcoming the bacterial challenge and improving wound healing. Nonetheless, the observations on the significantly high mortalities in Nile tilapia during the OTC-therapy period are a serious cause for concern, which require prudent planning on its suitability in tropical aquaculture.

Funding: The research was funded by the Indian Council of Agricultural Research, Government of India, New Delhi under the All India Network Project on Fish Health (Grant F. No. CIBA/AINP-FH/2015-16 dated 02.06.2015).

Acknowledgments: The authors thank the Vice-Chancellor, West Bengal University of Animal and Fishery Sciences, Kolkata for providing necessary infrastructure facility to carry out the work.

Conflicts of Interest: The authors declare that there is no conflict of interest.

\section{REFERENCES}

1. El-Sayed AFM. Stress and diseases. In: El-Sayed AFM. editor, Tilapia Culture. Cambridge: CABI Publishing, 2006; p. 149-151.

2. FAO. The State of World Fisheries and Aquaculture 2018 - Meeting the sustainable development goals. FAO, Rome, 2018. 210p. http://www.fao.org/3/19540EN/i9540en.pdf

3. Behera BK, Pradhan PK, Swaminathan TR, Sood N, Paria P, Das BK, et al. Emergence of tilapia lake virus associated with mortalities of farmed Nile tilapia Oreochromis niloticus (Linnaeus 1758) in India. Aquaculture 2018; 484: 168-174.

4. Pretto-Giordano LG, Müller EE, Freitas JCD, Silva VG. Evaluation on the pathogenesis of Streptococcus agalactiae in Nile tilapia (Oreochromis niloticus). Braz Arch Biol Technol. 2010; 53(1): 87-92.

5. Austin B, Austin DA. Bacterial Fish Pathogens: Disease of Farmed and Wild Fish. $5^{\text {th }}$ edition. Springer-Praxis in Aquaculture in Fisheries, Chichester: Praxis Publication Ltd, UK, 2012. 457 p.

6. Chi TTK, Clausen JH, Van PT, TersbøI B, Dalsgaard A. Use practices of antimicrobials and other compounds by shrimp and fish farmers in Northern Vietnam. Aquacult Rep. 2017; 7: 40-47.

7. Serrano PH. Responsible Use of Antibiotics in Aquaculture. FAO Fisheries Technical Paper No. 469, Rome: FAO, Italy, 2005; $97 \mathrm{p}$.

8. Noga EJ. Fish Disease: Diagnosis and Treatment. $2^{\text {nd }}$ edition. Ames, lowa: John Wiley and Sons Publications, 2010.

9. Romero J, Feijoo CG, Navarrete P. Antibiotics in aquaculture - Use, abuse and alternatives. Health and Environment in Aquaculture, Agricultural and Biological Sciences, InTech. 2012. Available

from http://www.intechopen.com/books/health-and-environment-inaquaculture/antibiotics-in-aquacult ure-use-abuse-and-alternatives. [Accessed on 12.3.2016]. 
10. Bondad-Reantaso MG, Arthur JR, Subasinghe RP. Improving Biosecurity Through Prudent and Responsible Use of Veterinary Medicines in Aquatic Food Production. FAO Fisheries and Aquaculture Technical Paper No. 547. Rome: FAO, Italy, 2012; 207 p.

11. USFWS. Approved Drugs for Use in Aquaculture. $2^{\text {nd }}$ edition. U.S. Fish and Wildlife Service's Aquatic Animal Drug Approval Partnership Program, American Fisheries Society's Fish Culture and Fish Health Sections, Association of Fish and Wildlife Agencies, and Fisheries and Water Resources; Policy Committee's Drug Approval Working Group. 2015, 38p. Available online at https://www.fws.gov/fisheries/aadap/PDF/ 2nd-Edition-FINAL.pdf [Accessed on 10.7.2017]

12. USFDA. Aquaculture. Silver Spring: U. S. Food and Drug Administration [Online], 2017. Available from: https://www.fda.gov/AnimalVeterinary/DevelopmentApprovalProcess/Aquaculture/default. htm [Accessed on 10.7.2017]

13. Menaga M, Fitzsimmons K. Growth of the tilapia industry in India. World Aquacult. 2017; 48(3): 49-52.

14. Yilmaz S. Effects of dietary caffeic acid supplement on antioxidant, immunological and liver gene expression responses, and resistance of Nile tilapia, Oreochromis niloticus to Aeromonas veronii. Fish Shellfish Immunol. 2019; 86: 384-392.

15. Julinta RB, Roy A, Singha J, Abraham TJ, Patil PK. Evaluation of efficacy of oxytetracycline oral and bath therapies in Nile tilapia, Oreochromis niloticus against Aeromonas hydrophila infection. Int J Curr Microbiol Appl Sci. 2017a; 6(7): 62-76.

16. Julinta RB, Abraham TJ, Roy A, Singha J, Dash G, Nagesh TS, Patil PK. Histopathology and wound healing in oxytetracycline treated Oreochromis niloticus (L.) against Aeromonas hydrophila intramuscular challenge. J Aquac Res Dev. 2017b; 8: 4.

17. OIE. Aquatic Animal Health Code. $16^{\text {th }}$ edition. Paris: World Organisation for Animal Health, France, 2013; $284 \mathrm{p}$.

18. Collins CH, Lyne PM, Grange JM, Falkinham III JO. Collins and Lyne's Microbiological Methods. $8^{\text {th }}$ edition. London: Arnold, UK, 2004; $456 \mathrm{p}$.

19. Figueras MJ, Alperi A, Beaz-Hidalgo R, Stackebrandt E, Brambilla E, Monera A, Marti'nez-Murcia AJ. Aeromonas rivuli sp. isolated from the upstream region of a karst water rivulet. Int J Syst Evol Microbiol. 2011; 61: 242-248.

20. Soto-Rodriguez SA, Cabanillas-Ramos J, Alcaraz U, GomezGil B. Romalde JL. Identification and virulence of Aeromonas dhakensis, Pseudomonas mosselii and Microbacterium paraoxydans isolated from Nile tilapia, Oreochromis niloticus, cultivated in Mexico. J Appl Microbiol. 2013; 115: 654-662.

21. Adikesavalu H, Patra A, Banerjee S, Sarkar A, Abraham TJ. Phenotypic and molecular characterization and pathology of Flectobacillus roseus causing flectobacillosis in captive held carp Labeo rohita (Ham.) fingerlings. Aquaculture 2015; 439: 60-65

22. Eden PA, Schmidt TM, Blakemore RP, Pace NR. Phylogenetic analysis of Aquaspirillum magnetotacticum using polymerase chain reaction-amplified 16SrRNA-specific DNA. Int J Syst Bacteriol. 1991; 41(2): 324-325.

23. Kumar S, Stecher G, Tamura K. MEGA7: Molecular evolutionary genetics analysis version 7.0 for bigger datasets. Mol Biol Evol. 2016; 33 (7): 1870-1874.

24. APHA/AWWA/WEF. Standard Methods for Examination of Water and Wastewater. $22^{\text {nd }}$ edition, Washington: American Public Health Association, USA. 2012. 
25. Bharadwaj A, Abraham TJ, Joardar SN. Immune effector activities in challenged rohu, Labeo rohita after vaccinating with Aeromonas bacterin. Aquaculture 2013; 392-395: 16-22.

26. Reed LJ, Muench $\mathrm{H}$. A simple method of estimating fifty percent endpoints. Am J Epidemiol. 1938; 27 (3): 493-497.

27. Bernet D, Schmidt H, Meier W, Burkhardt-Holm P, Wahli T. Histopathology in fish: Proposal for a protocol to assess aquatic pollution. J Fish Dis. 1999; 22: 25-34.

28. Santos Y, Toranzo AE, Baja JL, Nieto TP, Vila TG. Virulence properties and enterotoxin production of Aeromonas strains from fish culture systems. Infect Immun. 1988; 56: 3285-3293.

29. Schlotfeldt HJ, Alderman DJA. Practical guide for the freshwater fish farmer. Bull Eur Assoc Fish Pathol. 1995; 15 (4): 134-157.

30. Russo R, Mitchell H, Yanong RPE. Characterization of Streptococcus iniae isolated from ornamental cyprinid fishes and development of challenge models. Aquaculture 2006; 256: 105-110.

31. Ventura MT, Grizzle JM. Evaluation of portals of entry of Aeromonas hydrophila in channel catfish. Aquaculture 1987; 65: 205-214.

32. Bruun M, Madsen SL, Dalsgaad I. Efficiency of oxytetracycline treatment in rainbow trout experimentally infected with Flavobacterium psychrophilum strains having different in vitro antibiotic susceptibilities. Aquaculture 2003; 215(1-4): 11-20.

33. Haque SS, Reza MS, Sharker MR, Rahman MM, Islam MA. Effectiveness of oxytetracycline in reducing the bacterial load in rohu fish (Labeo rohita, Hamilton) under laboratory culture condition. J Coast Life Med. 2014; 2: 259-263.

34. Guerra RR, Santos NP, Cecarelli P, Silva JRMC, Hernandez-Blazquez FJ. Healing of skin wounds in the African catfish Clarias gariepinus. J Fish Biol. 2008; 73(3): 572-583.

35. Rehulka J. Aeromonas causes severe skin lesions in rainbow trout (Oncorhynchus mykiss): clinical pathology, haematology and biochemistry. Acta Vet Brno 2002; 71: 351-360

36. Quilhac A, Sire JY. Spreading, proliferation and differentiation of the epidermis after wounding a cichlid fish, Hemichromis bimaculatus. Anat Rec. 1999; 254: 435-451.

37. Ashley LM, Halver JE, Smith RR. Ascorbic acid deficiency in rainbow trout and coho salmon and effects on wound healing. In: Ribelin, W.E., Migaki, E. editors, The Pathology of Fishes. Madison: University of Wisconsin Press, 1975; p. 769-786.

38. Bereiter-Hahn J, Zylberberg L. Regeneration of teleost fish scale. Comp Biochem Physiol. 1993; 105A: 625-641.

39. Ohira Y, Shimizu M, Ura K, Takagi Y. Scale regeneration and calcification in goldfish Carassius auratus: quantitative and morphological processes. Fish Sci. 2007; 73: 46-54.

40. Wahli T, Verlhac V, Girling P, Gabaudan J, Aebischer C. Influence of dietary vitamin C on the wound healing process in rainbow trout (Oncorhynchus mykiss). Aquaculture 2003; 225: 371-386.

41. Przybylska-Diaz DA, Schmidt JG, Vera-Jiménez NI, Steinhagen D, Nielsen ME. $\beta$-glucan enriched bath directly stimulates the wound healing process in common carp (Cyprinus carpio L.). Fish Shellfish Immunol. 2013; 35: 998-1006.

42. Dutta M, Rai AK. Pattern of cutaneous wound healing in a live fish Clarias batrachus (L.) (Clariidae, Pisces). J Indian Fish Assoc. 1994; 24: 107-113. 
43. Vieira FA, Gregório SF, Ferraresso S, Thorne MA, Costa R, Milan M, et al. Skin healing and scale regeneration in fed and unfed sea bream, Sparus auratus. BMC Genomics 2011; 12: 490. BY NC) license (https://creativecommons.org/licenses/by-nc/4.0/). 